Check for updates

Cite this: RSC Adv., 2018, 8, 14129

Received 24th November 2017 Accepted 9th April 2018

DOI: 10.1039/c7ra12756a

rsc.li/rsc-advances

\section{Coordinating influence of multilayer graphene and spherical SnAgCu for improving tribological properties of a $20 \mathrm{CrMnTi}$ material}

\begin{abstract}
Xiaoxue Li (iD ${ }^{\text {ab }}$ and Jingli $\mathrm{Xu}^{* a}$
In order to increase the service life and operational reliability of a $20 \mathrm{CrMnTi}$-steel-based gearing system, the friction and wear behavior of $20 \mathrm{CrMnTi}$ needs to be further improved. In this study, the sliding friction and wear properties of 20CrMnTi, 20CrMnTi-1.50 wt\% graphene (20-Gr), 20CrMnTi-15.00 wt\% SnAgCu (20$\mathrm{Sn})$, and 20 CrMnTi-15.00 wt\% SnAgCu-1.50 wt\% graphene (20-Gr-Sn) were examined on a ball-on-disk tribometer. The friction and wear properties at 0-85 min of 20-Gr-Sn were significantly better compared to those of 20CrMnTi, 20-Gr, and 20-Sn. Metallic oxides appeared on the smooth wear scar of 20-Gr-Sn, which were tightly combined with the 20CrMnTi-based material. This caused a lubrication film with low hardness (approximately $1.25 \mathrm{GPa}$ ) to form on the grain-refined layer with high hardness (approximately $5.92 \mathrm{GPa}$ ). Graphene and $\mathrm{SnAgCu}$ in the lubrication film exhibited excellent coordinating lubrication to result in a low friction coefficient and lower wear rate. The obtained results can provide a good reference for increasing the service life of $20 \mathrm{CrMnTi}$-steel-based gear systems.
\end{abstract}

\section{Introduction}

With the heavy-duty and high-speed development of automobiles, a gear system is an indispensable element for the momentum transmission of machine components. ${ }^{\mathbf{1 - 4}}$ 20CrMnTi steel is regarded as an excellent material for manufacturing gear systems. ${ }^{5-9}$ However, under some extreme conditions, such as high temperature and high vacuum, oil and grease are not sufficient to provide optimal lubrication for a 20CrMnTi-based-gear system, which is an obstacle to increasing service life and operational reliability of such a system..$^{\mathbf{1 0 1 1}}$ Hence, it is necessary to improve the friction and wear behavior of 20CrMnTi steel.

An effective method of improving the friction and wear behavior of $20 \mathrm{CrMnTi}$ is to prepare 20CrMnTi-based selflubricating composites containing solid lubricants, such as graphene, ${ }^{12-14}$ carbon nanotubes (CNTs), ${ }^{15,16}$ and silver. ${ }^{17,18} \mathrm{Zhai}$ et al. ${ }^{12}$ explored the mechanical and tribological behaviors of a $\mathrm{Ni}_{3} \mathrm{Al}$-multilayer graphene composite. Their results indicated that multilayer graphene enhanced the mechanical properties of a $\mathrm{Ni}_{3} \mathrm{Al}$-based composite. The observed small friction coefficient and low wear rate were mainly attributed to the intralamellar separation of multilayer graphene. Mallikarjuna et al. ${ }^{15}$ reported that CNTs reinforced the friction and wear behavior of the composite, and they further found that CNTs

${ }^{a}$ School of Mechanical and Electronic Engineering, Wuhan University of Technology, 122 Luoshi Road, Wuhan 430070, China. E-mail: xujl1996@163.com

${ }^{b}$ School of Mechanical and Traffic Engineering, Ordos Institute of Technology, 1 Ordos Avenue East, Ordos 017000, China can effectively improve the anti-friction and anti-wear properties of as-prepared samples. Tronci et al. ${ }^{17}$ investigated the friction and wear behavior of silver, and found that its excellent friction and wear behavior was mainly attributed to the plastic deformation and ductility behavior of silver. However, to the best of our knowledge, few works have reported the synergetic lubrication of graphene and $\mathrm{SnAgCu}$ for improving the friction and wear properties of 20CrMnTi steel.

In this study, to better study the coordinating lubrication of graphene and SnAgCu, 20CrMnTi, 20CrMnTi-1.50 wt\% graphene (20-Gr), 20CrMnTi-15.00 wt\% SnAgCu (20-Sn), and 20CrMnTi-15.00 wt\% SnAgCu-1.50 wt\% graphene (20-Gr-Sn) samples were prepared by spark plasma sintering. Using a HT-1000 ball-on-disk tribometer, the tribological properties of as-prepared samples sliding against GCr15 balls were measured according to the ASTM Standard of G99-95. ${ }^{19}$ With the help of an electron probe microanalyzer (EPMA), the main wear mechanism was investigated by analyzing wear-scar morphology. Field-emission scanning electron microscopy (FESEM) was adopted to observe the cross-sectional morphology of wear scars. The main element contents in wear-scar cross-sections were tested using energy-dispersive spectroscopy (EDS), and Xray photoelectron spectroscopy (XPS) was used to analyze the phase components on the wear scars.

\section{Experimental details}

\subsection{Material preparation}

The starting powders (wt\%) of $0.34 \mathrm{Si}, 1.22 \mathrm{Cr}, 0.96 \mathrm{Mn}, 0.13 \mathrm{Ti}$, and $97.35 \mathrm{Fe}$ were mechanically mixed for $50 \mathrm{~min}$ by the 
Table 1 Main parameters of commercial powder for preparing 20CrMnTi-based material

\begin{tabular}{lllllll}
\hline Starting powders & Graphene & SnAgCu & Fe & Cr & Mn & Ti \\
\hline Purity $(\%)$ & $\geq 99.50$ & $\geq 99.50$ & $\geq 99.50$ & $\geq 99.00$ & $\geq 97.50$ & $\geq 98.50$ \\
Size $\left(\mathrm{nm} \mu \mathrm{m}^{-1}\right)$ & $\leq 20 \mathrm{~nm}$ & $\leq 20 \mu \mathrm{m}$ & $\leq 15 \mu \mathrm{m}$ & $\leq 20 \mu \mathrm{m}$ & $\leq 15 \mu \mathrm{m}$ & $\leq 25 \mu \mathrm{m}$
\end{tabular}

vibration milling at a frequency of $55 \mathrm{~Hz}$. Table 1 lists the main parameters of commercial powders for preparing 20CrMnTibased material. As can be seen from the table, the powder purity used in this study exceeded $97.50 \%$, and the powder size was mainly distributed in the region 0-25 $\mu \mathrm{m}$. A 20CrMnTi sample (30 $\mathrm{mm}$ in diameter and $20 \mathrm{~mm}$ high) was prepared in a cylindrical graphite mold measuring $30 \mathrm{~mm}$ in inner diameter on the spark plasma sintering (SPS) on a D. R. Sinter® SPS3.20 system. Under the protective environment of Ar gas, the heating rate, sintering temperature, fabrication time, and holding pressure were chosen as $95-112{ }^{\circ} \mathrm{C} \min ^{-1}, 950-1152{ }^{\circ} \mathrm{C}, 10-$ $20 \mathrm{~min}$ and 30-35 $\mathrm{MPa}$, respectively.

Table 2 shows the main components of 20CrMnTi-based composites. As can be seen from the table, approximately $15 \mathrm{wt} \% \mathrm{SnAgCu}$ and $1.50 \mathrm{wt} \%$ graphene were chosen to prepare the 20-Gr, 20-Sn, and 20-Gr-Sn composites. The commercial multilayer graphene (5-20 nm thick and 0.5-20 $\mu \mathrm{m}$ in lateral dimension) and spherical SnAgCu powder (less than $20 \mu \mathrm{m}$ in diameter) were purchased from Nanjing XFNANO Materials Tech Co., Ltd. Table 3 shows the main elemental content of spherical $\mathrm{SnAgCu}$ powder. As shown in the table, approximately 93.70 wt\% Sn, $3.50 \mathrm{wt} \% \mathrm{Ag}$, and $2.80 \mathrm{wt} \% \mathrm{Cu}$ were contained in spherical $\mathrm{SnAgCu}$ powder.

Using a FESEM tested instrument, the typical morphologies of multilayer graphene, $\mathrm{SnAgCu}$ and 20-Gr-Sn based powder are shown in Fig. 1a, b, and c, respectively. The powder phase compositions are examined at the scanning speed of $0.01^{\circ} \mathrm{s}^{-1}$ using an X-ray diffractometer (XRD) with $\mathrm{Cu} \mathrm{K} \alpha$ radiation. The results are exhibited in Fig. 1d. As shown in Fig. 1d, the main $\mathrm{XRD}$ peaks indicate that graphene and $\mathrm{SnAgCu}$ of high purity were used to obtain 20Gr-Sn based powder using a vibration milling. As shown in Fig. 1c and d, multilayer graphene and $\mathrm{SnAgCu}$ dispersed homogeneously in 20Gr-Sn based powder.

\subsection{Vicker's microhardness and density}

Table 4 shows the main compositions and mechanical properties of the as-prepared samples. In accordance with the ASTM standard no. E92-82, ${ }^{20}$ the Vickers hardness values of the as-

Table 2 Main components of 20CrMnTi-based composites

\begin{tabular}{|c|c|c|c|c|c|c|c|}
\hline \multirow[b]{2}{*}{ Samples } & \multicolumn{2}{|c|}{$\begin{array}{l}\text { Lubricant addition } \\
\text { contents (wt } \%)\end{array}$} & \multicolumn{5}{|c|}{ 20CrMnTi based material (wt\%) } \\
\hline & Graphene & $\mathrm{SnAgCu}$ & $\mathrm{Fe}$ & $\mathrm{Cr}$ & Mn & $\mathrm{Ti}$ & $\mathrm{Si}$ \\
\hline 20-Gr & 1.50 & - & 97.35 & 1.22 & 0.96 & 0.13 & \\
\hline 20-Sn & - & 15.00 & 97.35 & 1.22 & 0.96 & 0.13 & \\
\hline 20-Gr-Sn & 1.50 & 15.00 & 97.35 & 1.22 & 0.96 & 0.13 & \\
\hline
\end{tabular}

prepared samples were measured using a HVS-1000 hardness tester, and the results are listed in Table 4. According to ASTM standard no. B962-08 and Archimedes' principle, ${ }^{21}$ the densities of the 20CrMnTi, 20-Gr, 20-Sn, and 20-Gr-Sn samples were measured, and the results are listed in Table 4 .

\subsection{Friction and wear measurement}

According to the ASTM standard no. G99-95, at $5 \mathrm{~N}-0.2 \mathrm{~m} \mathrm{~s}^{-1}, 10$ $\mathrm{N}-0.4 \mathrm{~m} \mathrm{~s}^{-1}, 15 \mathrm{~N}-0.6 \mathrm{~m} \mathrm{~s}^{-1}$, and $20 \mathrm{~N}-0.8 \mathrm{~m} \mathrm{~s}^{-1}$, the tribological behaviors of the as-prepared samples $(30 \mathrm{~mm}$ in diameter and $20 \mathrm{~mm}$ in height) sliding against GCr15 balls (6 $\mathrm{mm}$ in diameter) were evaluated using the HT-1000 ball-on-disk tribometer. Before being measured, the sample surfaces were mechanically polished using emery papers of less than 1200 grits. The rotated disks of the as-prepared samples were cleaned by liquid acetone and dried using hot air. The friction radius in this study was chosen as $4.5 \mathrm{~mm}$. At a relative humidity of $50-70 \%$, the friction coefficients of the as-prepared samples were continuously recorded by the HT1000 computer-controlled system. During the friction and wear process, the wear rate $W$ was defined by $W=U /(P \cdot L)=(A \cdot Q) /(F \cdot C) \cdot{ }^{19}$ Herein, $C, P$, and $U$ denote the sliding distance in $\mathrm{mm}$, applied load in $N$, and wear volume in $\mathrm{mm}^{3}$, respectively. $Q$ denotes the circle perimeter of wear scar in $\mathrm{mm}$. $A$ is the mean cross-section area of wear scar in $\mathrm{mm}^{2}$, which can be calculated using a surface profiler (ST400, Nanovea Corp., USA). Fig. 2 shows the typical wear-scar morphology of the as-prepared samples. As can be seen from the figure, when the test stylus of the ST400 profiler slowly moved across the wear scar along the measured line $A B$ (see Fig. 2a), the coordinate positions of the test stylus were continuously recorded to form a two-dimensional (2D) profile of the wear scar (see Fig. 2b). Similarly, other measurements along the lines CD, $\mathrm{EF}$, and HI were also carried out. After carrying out the sliding wear measurements, the mean cross-sectional area $A$ of the wear scar was obtained to calculate the wear rate $W$.

\section{Result and discussion}

\subsection{Phase research and element distribution}

Fig. 3a and b show typical FESEM cross-section morphologies of 20-Gr and 20-Sn. As shown in Fig. 3a, multilayer graphene was tightly embedded in 20-Gr. The multilayer morphology of graphene is well exhibited in the rectangular region of Fig. 3a. As

Table 3 Main elemental content of spherical SnAgCu powder

\begin{tabular}{llll}
\hline Main elements & $\mathrm{Sn}$ & $\mathrm{Ag}$ & $\mathrm{Cu}$ \\
Content (wt\%) & $93.70 \pm 0.32$ & $3.50 \pm 0.23$ & $2.80 \pm 0.14$
\end{tabular}



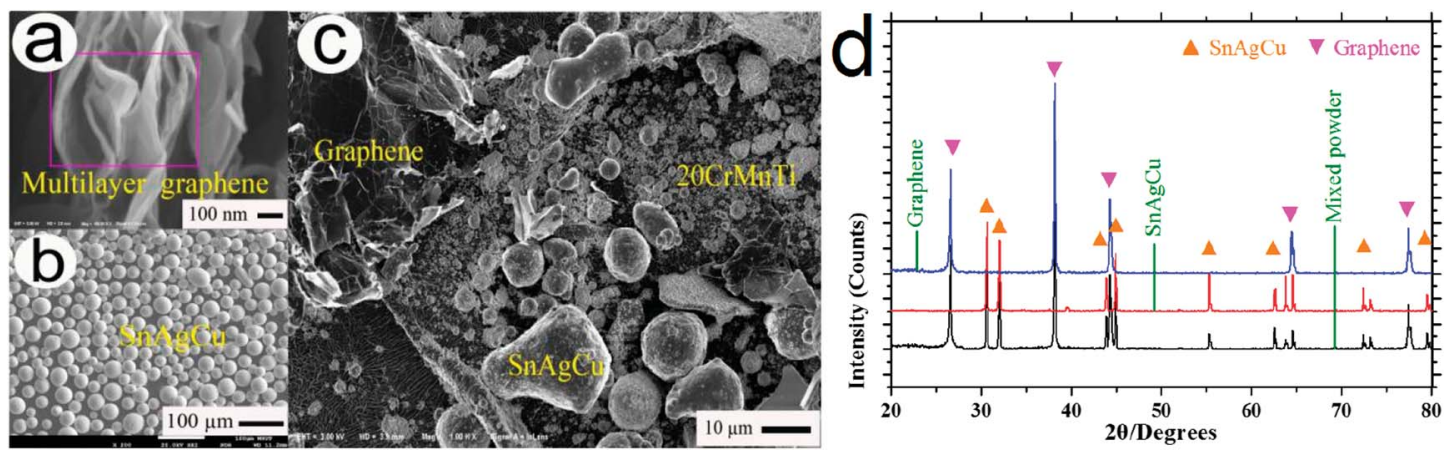

Fig. 1 Typical FESEM morphologies (a-c) and XRD pattern (d) of multilayer graphene, SnAgCu and 20-Gr-Sn based powder.

Table 4 Main compositions and mechanical properties of as-prepared samples

\begin{tabular}{llll}
\hline Samples & Compositions (wt\%) & Density $\left(\mathrm{g} \mathrm{cm}^{-3}\right)$ & Hardness $(\mathrm{GPa})$ \\
\hline $20 \mathrm{CrMnTi}$ & $0.34 \mathrm{Si}, 1.22 \mathrm{Cr}, 0.96 \mathrm{Mn}, 0.13 \mathrm{Ti}$ and $97.35 \mathrm{Fe}$ & $7.86 \pm 0.11$ & $5.22 \pm 0.03$ \\
$20-\mathrm{Gr}$ & 20CrMnTi-1.50 wt\% graphene & $7.21 \pm 0.15$ & $5.86 \pm 0.04$ \\
$20-\mathrm{Sn}$ & 20CrMnTi-15.00 wt\% SnAgCu & $7.78 \pm 0.13$ & $5.55 \pm 0.05$ \\
$20-\mathrm{Gr}-\mathrm{Sn}$ & 20CrMnTi-1.50 wt\% graphene-15.00 wt\% SnAgCu & $7.54 \pm 0.12$ & $5.22 \pm 0.06$
\end{tabular}

shown in Fig. 3b, spherical SnAgCu was well combined with 20Sn-based composite. Fig. 3c shows a typical XRD pattern of the 20-Gr-Sn sample prepared by SPS. As can be seen from Fig. 3c, the phase compositions of 20-Gr-Sn are mainly composed of 20CrMnTi, SnAgCu, and graphene according to the XRD intensities of the main diffraction peaks.

\subsection{Analysis of friction coefficients and wear rates}

Fig. 4a is a schematic of sample/ball tribo-pairs. As shown in Fig. 4a, the as-prepared samples were driven to slide against a fixed GCr15 ball on the high-temperature, ball-on-disk HT1000 tribometer. The measured friction and wear behaviors of 20CrMnTi under different test conditions are shown in Fig. 4b and c. As exhibited in the figures, the tribological behavior of 20CrMnTi was significantly better at $15 \mathrm{~N}-0.6 \mathrm{~m} \mathrm{~s}^{-1}$ than those at $5 \mathrm{~N}-0.2 \mathrm{~m} \mathrm{~s}^{-1}, 10 \mathrm{~N}-0.4 \mathrm{~m} \mathrm{~s}^{-1}$, and $20 \mathrm{~N}-0.8 \mathrm{~m} \mathrm{~s}^{-1}$.

Fig. 5 shows the typical friction coefficients and wear rates of the as-prepared samples at $15 \mathrm{~N}-0.6 \mathrm{~m} \mathrm{~s}^{-1}$. As can be seen from the figure, during the sliding wear process of $0-85 \mathrm{~min}$, the friction coefficients and wear rates of 20-Gr-Sn were smaller than those of 20CrMnTi, 20-Gr, and 20-Sn.

In order to further study the influence of graphene and $\mathrm{SnAgCu}$ on the tribological behavior of $20 \mathrm{CrMnTi}$, the wear-scar morphologies of 20CrMnTi, 20-Gr, 20-Sn and 20-Gr-Sn must be investigated in detail.

\subsection{Analysis of wear-scar morphology}

Fig. 6 shows the typical EPMA morphologies of wear scars of 20CrMnTi, 20-Gr, and 20-Sn at $85 \mathrm{~min}$. As shown in Fig. 6a, large peeling bits appeared on the wear scars, indicating that the main wear mechanism of 20CrMnTi is severe peeling. As shown in Fig. 6b, large ploughing and plastic deformation bodies formed on the wear scars, indicating that the main wear mechanisms of 20-Gr were ploughing and plastic deformation. As shown in Fig. 6c, slight ploughing and small plastic deformation bodies exist on the wear scars at $85 \mathrm{~min}$. Therefore, the main wear mechanisms of 20-Sn were determined to be plastic deformation and slight ploughing. According to Yang et al., ${ }^{22}$ if compared to those of 20CrMnTi and 20-Gr (see Fig. 6a and b),
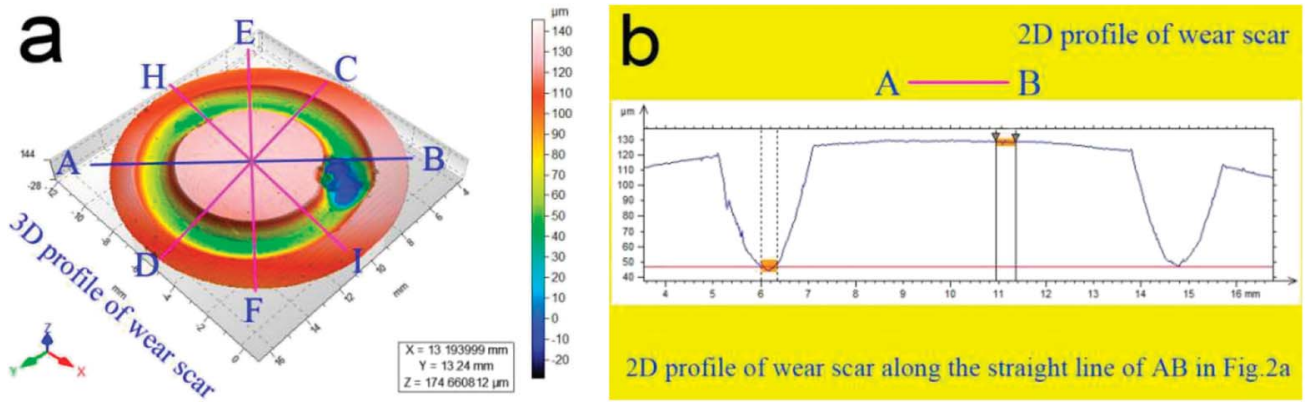

Fig. 2 Typical wear-scar morphology of as-prepared sample: 3D (a) and 2D (b) wear-scar profiles. 

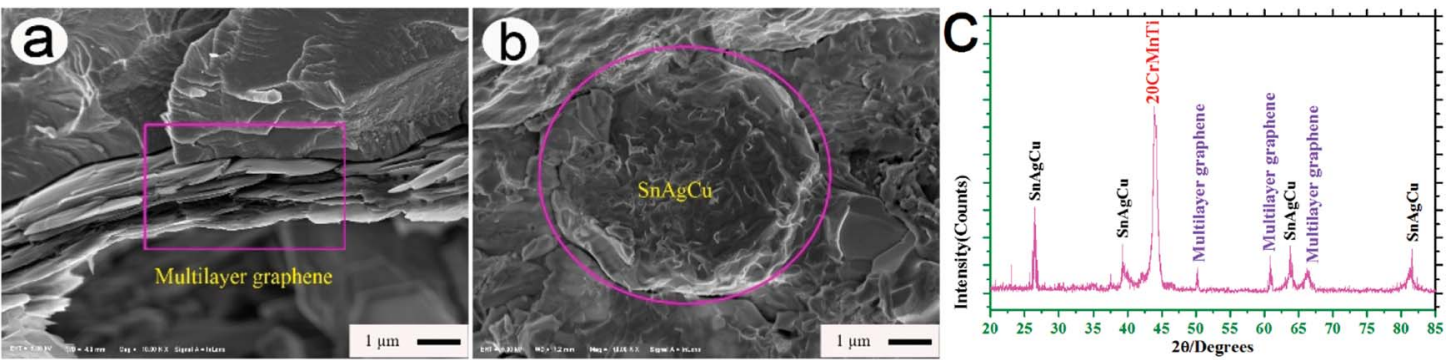

Fig. 3 Typical FESEM cross-section morphologies of 20-Gr (a) and 20-Sn (b), as well as the XRD pattern of 20-Gr-Sn sample prepared by SPS (c).
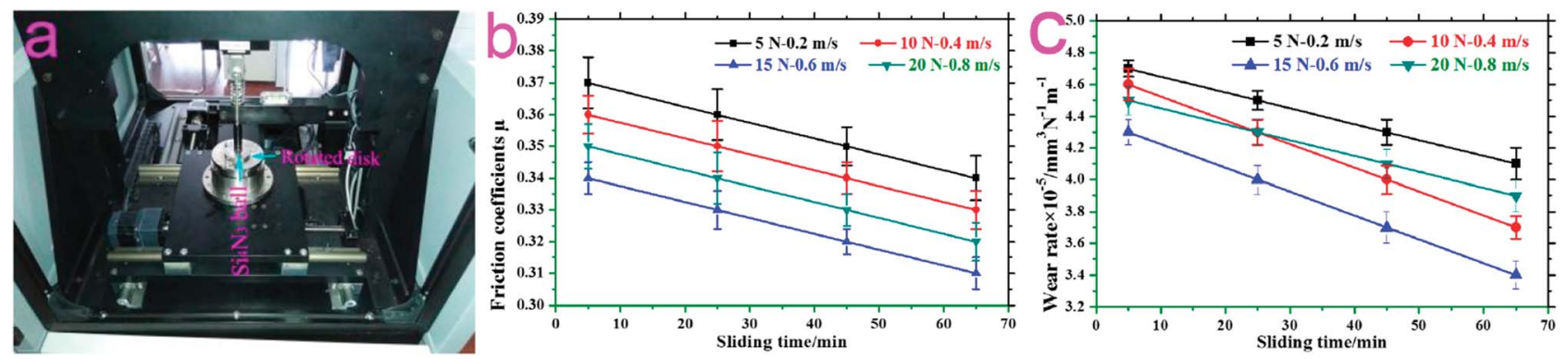

Fig. 4 Schematic of matching samples/ball tribo-pairs (a), friction coefficients (b), and wear rates (c) of 20CrMnTi samples obtained under different test conditions.

the main wear mechanisms of plastic deformation and slight ploughing (see Fig. 6c) were more helpful to realizing a low friction coefficient and small wear rate for 20-Sn.

Fig. 7 shows the typical XPS phase characterization of the wear scar of $20 \mathrm{CrMnTi}$ at $85 \mathrm{~min}$. As shown in the figure, with reference to the results of Zhang et al.,$^{23}$ Fan et al., ${ }^{24}$ Huang et al. ${ }^{25}$ and Yang et al. ${ }^{26}$ the main XPS diffraction peaks were mainly attributed to the metal oxides of $\mathrm{SnO}_{2}, \mathrm{Fe}_{3} \mathrm{O}_{4}, \mathrm{MnO}_{2}$, and $\mathrm{Cr}_{2} \mathrm{O}_{3}$. When sliding wear was carried out up to $85 \mathrm{~min}$, metal oxides such as $\mathrm{SnO}_{2}, \mathrm{Fe}_{3} \mathrm{O}_{4}, \mathrm{MnO}_{2}$, and $\mathrm{Cr}_{2} \mathrm{O}_{3}$ formed on wear scars, leading to a friction coefficient of approximately 0.32 and a wear rate of approximately $4.23 \times 10^{-5} \mathrm{~mm}^{3} \mathrm{~N}^{-1} \mathrm{~m}^{-1}$ (see Fig. 5).

Fig. 8a shows the typical EPMA morphology of the wear scar of 20-Gr-Sn. As shown in the figure, a plastic deformation body formed on the smooth wear scar at $85 \mathrm{~min}$, indicating that the main wear mechanism of $20-\mathrm{Gr}$-Sn is plastic deformation. Fig. 8b shows the typical FESEM morphology of the wear scar marked by rectangle A in Fig. 8a. As shown in Fig. 8b, graphene and $\mathrm{SnAgCu}$ appear on the wear scar.

According to the discussions of Yang et al. ${ }^{27}$ the surface texture of wear scars could be well evaluated using the height parameters of arithmetical mean height $\left(S_{\mathrm{a}}\right)$, root-mean-square height $\left(S_{\mathrm{q}}\right)$, height-distribution kurtosis $\left(S_{\mathrm{ku}}\right)$, and heightdistribution skewness $\left(S_{\text {sk }}\right)$. A ST400 surface profiler was used to characterize the surface texture of the wear scars. The square region ( $0.1 \mathrm{~mm}$ long) on the wear scar was measured at a scanning step length of $0.001 \mathrm{~mm}$. A scanning time of approximately $20 \mathrm{~min}$, the non-contact measurement scanning mode, and the scanning principle of the chromatic aberration of the whitelight axis were used in this study. Fig. 8c shows the typical texture structure of a wear scar at $85 \mathrm{~min}$. As can be seen from
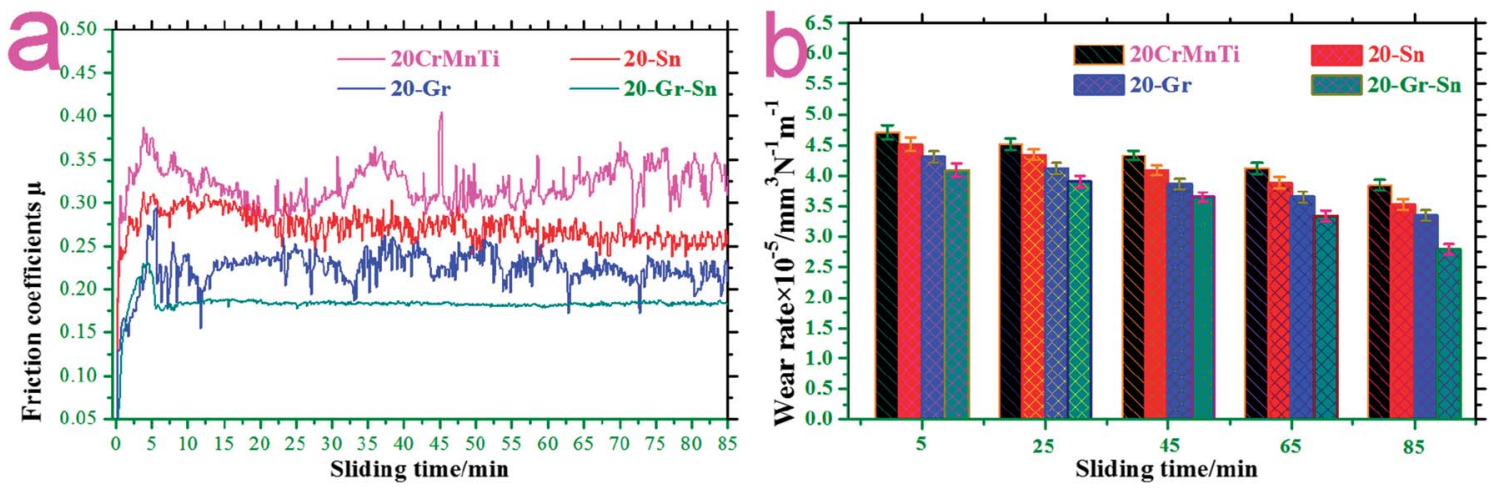

Fig. 5 Typical friction coefficients (a) and wear rates (b) of as-prepared samples at $15 \mathrm{~N}-0.6 \mathrm{~m} \mathrm{~s}^{-1}$. 


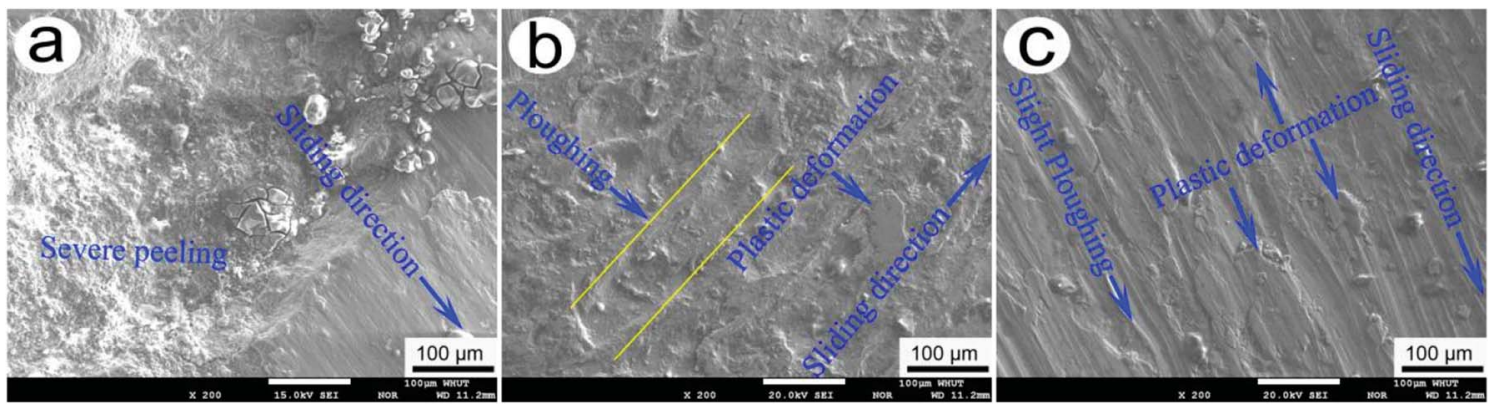

Fig. 6 Typical EPMA morphologies of wear scars of 20CrMnTi, 20-Gr, and 20-Sn samples at 85 min.

the figure, the small height parameters $\left(S_{\mathrm{a}}, 0.09 \mu \mathrm{m} ; S_{\mathrm{q}}, 0.11\right.$ $\mu \mathrm{m} ; S_{\mathrm{ku}}, 2.13$; and $\left.S_{\mathrm{sk}}, 0.23\right)$ indicate that the wear-scar morphology of 20-Gr-Sn is smooth according to the definition of Yang et al..$^{27,28}$

Fig. 9 shows the representative EPMA back-scattering morphology and main element distributions on the wear scar of $20-\mathrm{Gr}$-Sn at $85 \mathrm{~min}$. As shown in the figure, at $85 \mathrm{~min}$ multilayer graphene and $\mathrm{SnAgCu}$ are uniformly distributed on the wear scar.

Hence, massive $\mathrm{SnAgCu}$ appeared on the wear scar to undergo the significant plastic deformation at the repeating effect of friction force in Fig. 8a and b. The plastic deformation effectively repaired the wear scar to form a well-textured structure (see Fig. 8c). In addition, multilayer graphene possessed small intra-la adherence. During the process of sliding wear, graphene interlamination separation effectively prevented the surface material from being destroyed, resulting in low wear rate. The small shearing strength of $\mathrm{SnAgCu}$ is helpful in lowering the friction force, which is beneficial to the realizing a small friction coefficient. Hence, the excellent synergistic lubrication of graphene and SnAgCu caused 20-Gr-Sn to exhibit a small friction coefficient and a lower wear rate.
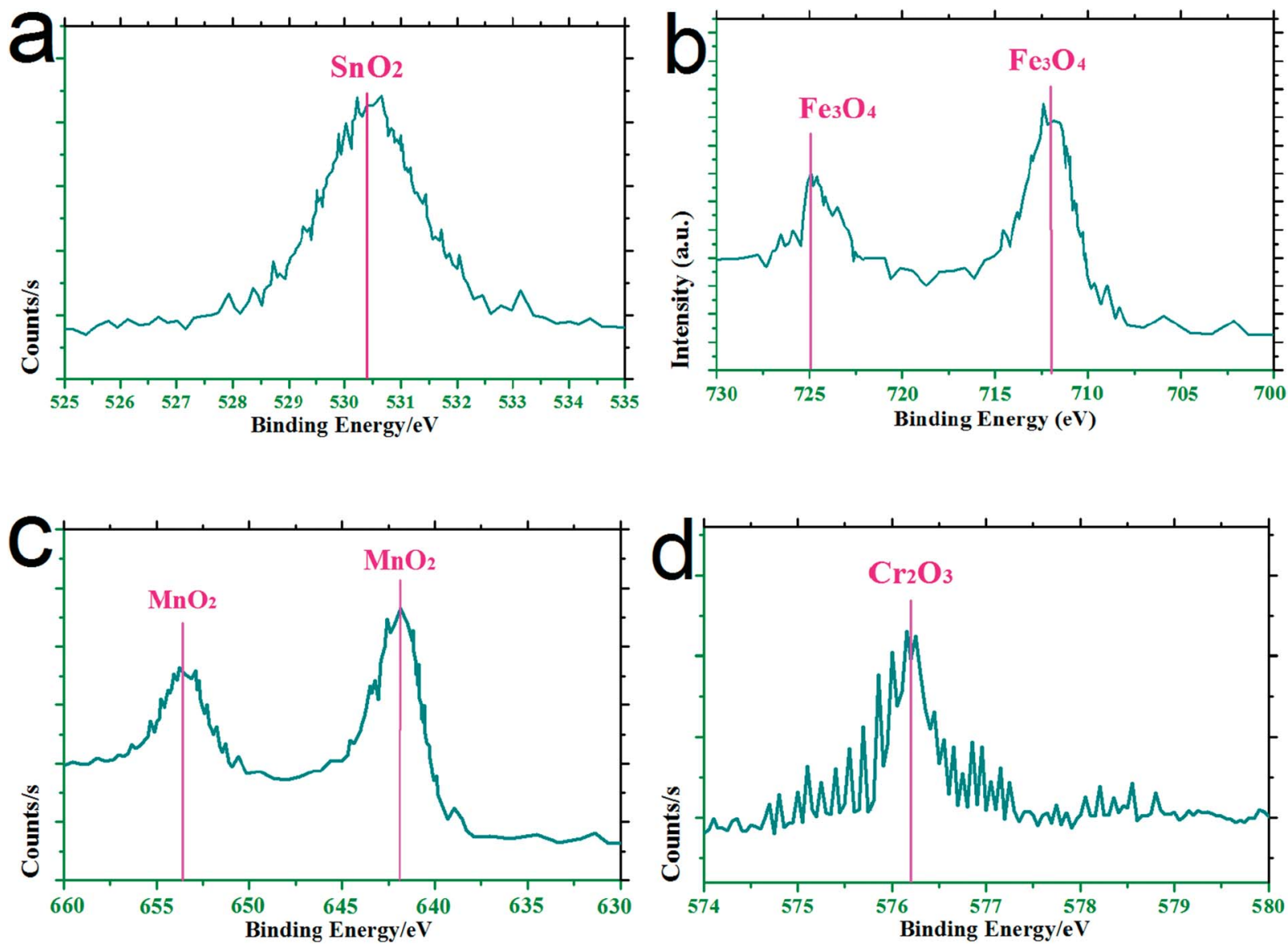

Fig. 7 Typical XPS phase characterization of the wear scar of 20CrMnTi at $85 \mathrm{~min}$. 

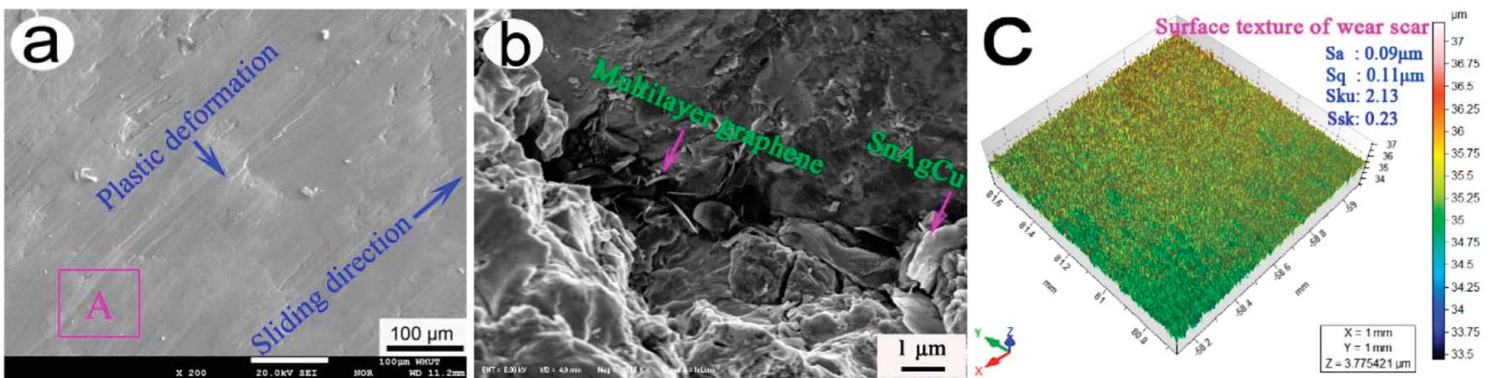

Fig. 8 Typical EPMA morphology of wear scar of 20-Gr-Sn (a), FESEM morphology of wear scar marked by rectangle A in a (b), and texture structure of wear scar at $85 \mathrm{~min}$ (c).
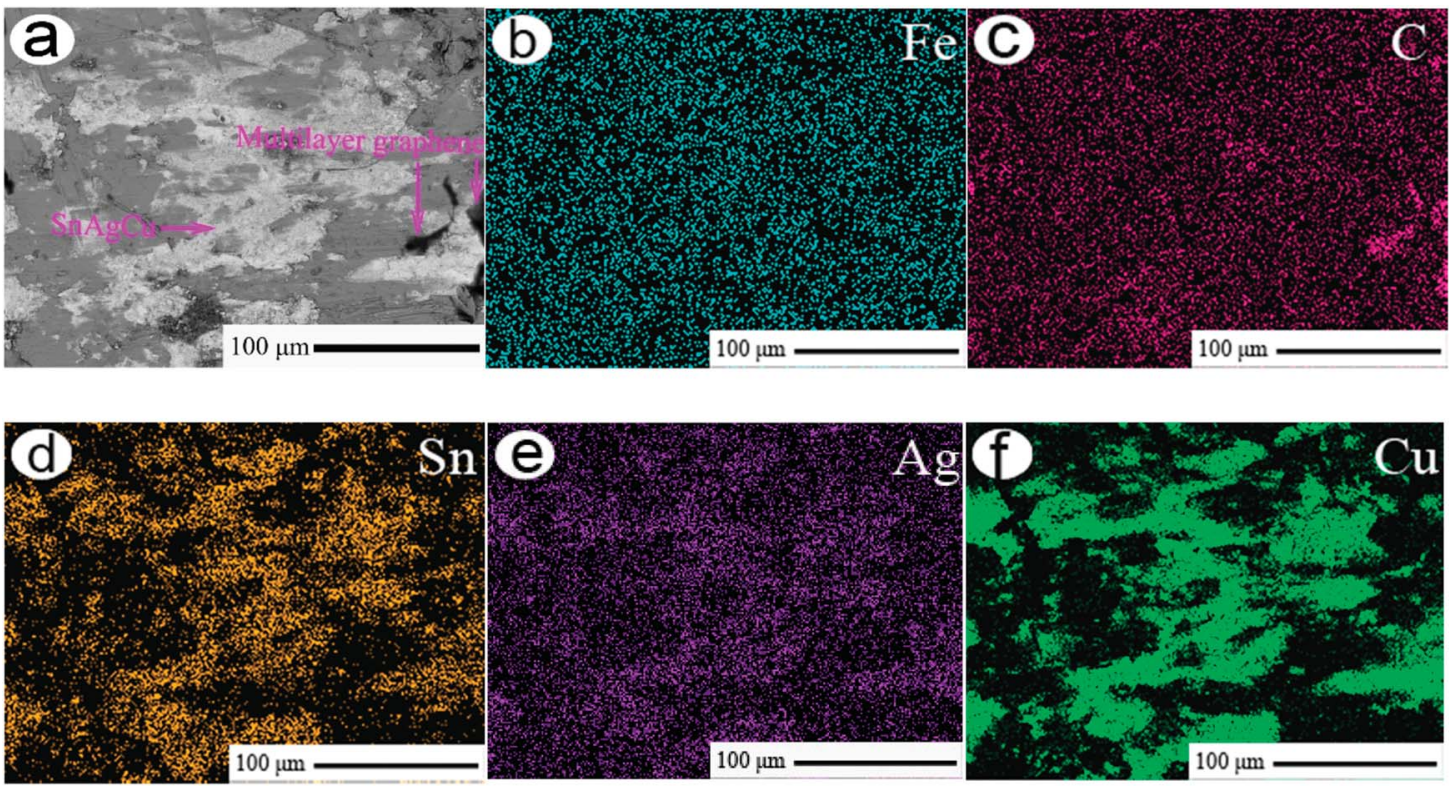

Fig. 9 Representative EPMA back-scattering morphology (a) and main element distributions (b-f) on wear scar of 20 -Gr-Sn at 85 min.

\subsection{Analysis of wear-scar cross-sections}

Fig. 10a shows the typical FESEM cross-sectional morphology of the wear scar of $20-\mathrm{Gr}-\mathrm{Sn}$ at $85 \mathrm{~min}$. As can be seen from the figure, the typical stratification structures existed under the wear-scar subsurface, and were mainly composed of lubrication film, a grain-refined layer, and 20CrMnTi-based material. Fig. 10b shows the main elemental content in the rectangular regions of B, C and D (see Fig. 10a). As shown in Fig. 10a and b, approximately $2.5 \mathrm{wt} \%$ graphene, $40 \mathrm{wt} \% \mathrm{SnAgCu}$, and $15 \mathrm{wt} \%$ metal oxides exist in the lubrication film. Graphene, $\mathrm{SnAgCu}$, and $\mathrm{O}$ contents in the grain-refined layer were approximately $1.65 \mathrm{wt} \%, 12.5 \mathrm{wt} \%$, and $4.5 \mathrm{wt} \%$, respectively. Fig. $10 \mathrm{c}$ is a schematic of the lubrication film structure. As can be seen in the figure, graphene, $\mathrm{SnAgCu}$, and metal oxides appear in the lubrication film, and were tightly combined with the 20CrMnTibased material, leading to the formation of the lubrication film. In accordance with Zhai et al., ${ }^{29}$ a lubrication film with
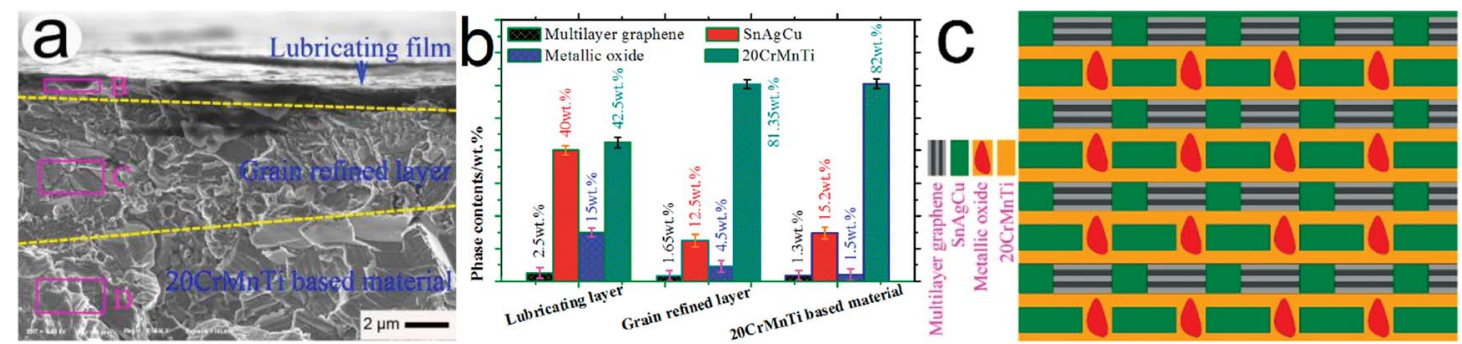

Fig. 10 Typical FESEM cross-sectional morphology of wear scar of 20-Gr-Sn (a); main element content in the rectangular regions B, C, and D in a (b); and schematic of lubrication-film structure (c) at 85 min. 

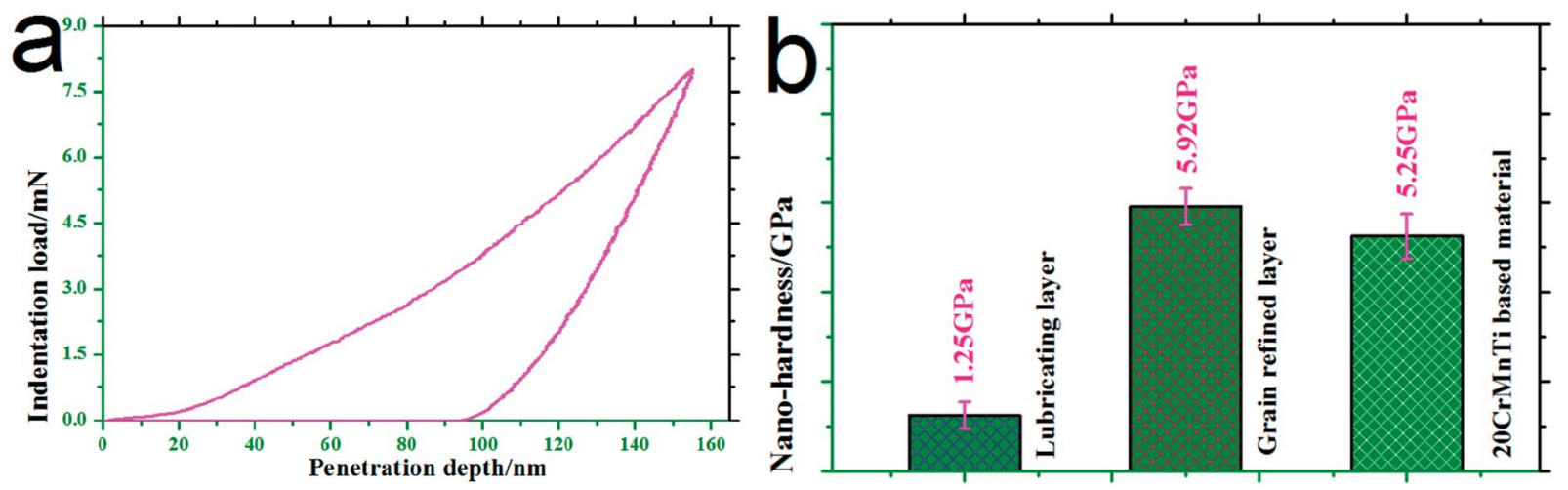

Fig. 11 Typical nano-indentation curve (a) and nano-indentation hardness (b) in wear scar cross-sections at 85 min.
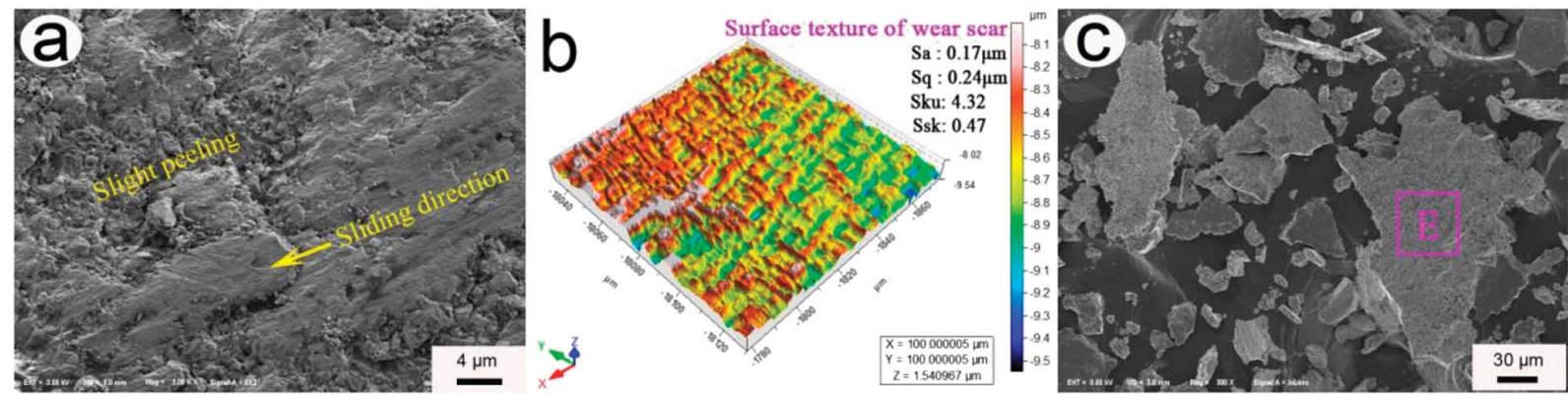

Fig. 12 Typical FESEM morphology of GCr15 ball (a), texture structure of wear scar (b), and FESEM morphology of wear debris (c) at 85 min.

graphene, $\mathrm{SnAgCu}$, and metal oxides resulted in a small friction coefficient and low wear rate.

Fig. 11 shows the typical nano-indentation curve and nanoindentation hardness in wear-scar cross-sections at $85 \mathrm{~min}$. As shown in the figure, after being tested, a massive amount of material, $40 \mathrm{wt} \% \mathrm{SnAgCu}$, existed in the lubrication film (see Fig. 10b), and the indentation hardness of the lubrication film was approximately $1.25 \mathrm{GPa}$. Indentation hardness values of approximately $5.92 \mathrm{GPa}$ for the grain-refined layer and approximately 5.25 GPa for 20CrMnTi-based material were obtained. During the friction and wear process of 0-85 min, a slight amount of graphene (2.5 wt\%) was gradually exposed to the wear scar, which was tightly combined with $\mathrm{SnAgCu}$, leading to the formation of a lubrication film. The lubrication film possessed a low hardness of $1.25 \mathrm{GPa}$, and existed on the grainrefined layer with a high hardness of $5.92 \mathrm{GPa}$. According to the ones proposed by Zhai et al. ${ }^{29}$ these values facilitated a low friction coefficient and low wear rate.

\subsection{Analysis of GCr15 ball}

Fig. 12a and b show the typical FESEM morphology of a GCr15 ball and the texture structure of its wear scar at $85 \mathrm{~min}$. As can be seen from the figure, slight peeling bits formed on the wear scar of GCr15 ball, indicating that the main wear mechanism was slight peeling. The low height parameters $\left(S_{\mathrm{a}}, 0.17 \mu \mathrm{m} ; S_{\mathrm{q}}\right.$, $0.24 \mu \mathrm{m} ; S_{\mathrm{ku}}, 4.32$; and $\left.S_{\mathrm{sk}}, 0.47\right)$ were obtained, indicating that the wear scar of the GCr15 ball was smooth. Fig. 12c shows the typical FESEM morphology of the wear debris at $85 \mathrm{~min}$. As shown in the figure, the main structure of the wear debris was in the form of a large sheet. The main element contents (wt\%) in the rectangle $\mathrm{E}$ of the wear debris in the figure were about 1.86 graphene-24.72 Sn-0.82 Ag-0.67 Cu-62.32 Fe-1.18 Cr-1.02 Mn$0.17 \mathrm{Ti}-7.24 \mathrm{O}$. Graphene and $\mathrm{SnAgCu}$ appeared on the wear scar of the GCr15 ball, indicating that graphene and $\mathrm{SnAgCu}$ were transferred to the matching-pair friction interface. This effectively lowered the friction resistance and material loss of 20-Gr-Sn, which greatly facilitated to realizing a small friction coefficient and low wear rate.

\section{Conclusions}

In this paper, we mainly explored the coordinating lubrication of graphene and $\mathrm{SnAgCu}$, reaching the following conclusions.

(1) At 0-85 min, a smaller friction coefficient and lower wear rate were obtained for 20-Gr-Sn compared to those of 20CrMnTi, 20-Gr, and 20-Sn samples.

(2) A massive amount of both graphene and $\mathrm{SnAgCu}$ existed on the smooth wear scar of 20-Gr-Sn, exhibiting excellent friction and wear properties, leading to a low friction coefficient and low wear rate.

(3) Graphene, SnAgCu, and metal oxides appeared on the wear scars of as-prepared samples, and combined with 20CrMnTi-based material, resulted in the formation of a lubrication film. 
(4) A lubrication film (1.25 GPa in hardness) existed on the high-hardness grain-refined layer $(5.92 \mathrm{GPa})$, which facilitated a low friction coefficient and low wear rate.

\section{Conflicts of interest}

There are no conflicts to declare.

\section{Acknowledgements}

The research was supported by the Science Research Project in the Inner Mongolia Autonomous Region for the Institution of Higher Learning (NJZZ16369) and 2025 Projects made in China (2159999), and Programs for Science and Technology Development and Trial Production of New Products(2017AA10102). The authors are also grateful to Nanjing XFNANO Materials Tech Co., Ltd., China, for their kind help with the powders used. We would like to thank LetPub (www.letpub.com) for providing linguistic assistance during the preparation of this manuscript.

\section{References}

1 T. S. Yang, Prediction of maximum forming load and billet dimensions using an abductive network and finite element method simulation of a near net-shaped helical gear forging, Proc. Inst. Mech. Eng., Part B, 2009, 223, 289-304.

2 J. S. Jin, J. C. Xia, X. Y. Wang, G. A. Hu and H. Liu, Die design for cold precision forging of bevel gear based on finite element method, J. Cent. South Univ. Technol., 2009, 16, 546-551.

3 A. A. Kamouneh, J. Ni, D. Stephenson and R. Vriesen, Diagnosis of involutometric issues in flat rolling of external helical gears through the use of finite-element models, Int. J. Mach. Tool. Manufact., 2007, 47, 1257-1262.

4 S. Y. Kim, S. Kubota and M. Yamanaka, Application of CAE in cold forging and heat treatment processes for manufacturing of precision helical gear part, J. Mater. Process. Technol., 2008, 201, 25-31.

5 L. You, L. Liqun and S. Lina, Effect of shot peening on the fatigue resistance of laser surface melted 20CrMnTi steel gear, Mater. Sci. Eng., A, 2015, 629, 8-15.

$6 \mathrm{X}$. Han and L. Hua, Friction behaviors in cold rotary forging of 20CrMnTi alloy, Tribol. Int., 2012, 55(2), 29-39.

7 X. H. Han and L. Hua, 3D FE modeling simulation for wear in cold rotary forging of 20CrMnTi alloy, J. Tribol., 2013, 135(1), 011101.

$8 \mathrm{X}$. H. Han and L. Hua, Investigation on contact parameters in cold rotary forging using a 3D FE method, Int. J. Adv. Des. Manuf. Technol., 2012, 62, 1087-1096.

9 X. B. Deng, L. Hua, X. H. Han and Y. L. Song, Numerical and experimental investigation of cold rotary forging of a 20CrMnTi alloy spur bevel gear, Mater. Des., 2011, 32, 1376-1389.

10 Y. Qin, D. Xiong and J. Li, Adaptive-lubricating PEO/Ag/ $\mathrm{MoS}_{2}$, multilayered coatings for Ti6Al4V alloy at elevated temperature, Mater. Des., 2016, 107, 311-321.
11 E. Omrani, A. D. Moghadam and P. L. Menezes. New emerging self-lubricating metal matrix composites for tribological applications, Ecotribology, Springer International Publishing, 2016, pp. 63-103.

12 W. Z. Zhai, X. L. Shi, J. Yao and A. M. M. Ibrahim, Investigation of mechanical and tribological behaviors of multilayer graphene reinforced $\mathrm{Ni}_{3} \mathrm{Al}$ matrix composites, Composites, Part B, 2015, 70, 149-155.

13 A. D. Moghadam, E. Omrani, P. L. Menezes and P. K. Rohatgi, Mechanical and tribological properties of self-lubricating metal matrix nanocomposites reinforced by carbon nanotubes (CNTs) and graphene-a review, Composites, Part B, 2015, 77, 402-420.

14 M. Tabandeh-Khorshid, E. Omrania, P. L. Menezes and P. K. Rohatgi, Tribological performance of self-lubricating aluminum matrix nanocomposites: role of graphene nanoplatelets, Engineering Science and Technology, an International Journal, 2016, 19(1), 463-469.

15 H. M. Mallikarjuna, K. T. Kashyap and P. G. Koppad, Microstructure and dry sliding wear behavior of $\mathrm{Cu}-\mathrm{Sn}$ alloy reinforced with multiwalled carbon nanotubes, Trans. Nonferrous Met. Soc. China, 2016, 26(7), 1755-1764.

16 L. Kumar and S. N. Alam, Mechanical properties, wear behavior and crystallographic texture of Al-multiwalled carbon nanotube composites developed by powder metallurgy route, J. Compos. Mater., 2017, 51(8), 1099-1117.

17 G. Tronci and M. B. Marshall, Understanding the behaviour of silver as a low friction coating in aerospace fasteners, Tribol. Int., 2016, 100, 162-170.

18 K. Yang, X. L. Shi, Y. C. Huang and Z. H. Wang, The research on the sliding friction and wear behaviors of 20CrMnTi$10 \mathrm{wt} \% \mathrm{Ag}$ at elevated temperatures, Mater. Chem. Phys., 2017, 186, 317-326.

19 ASTM Standards G99-95, Standard test method for wear testing with a pin-on-disk apparatus, ASTM Int., West Conshohocken PA, 1995.

20 ASTM E92-82, Standard test method for vickers hardness of metallic materials, ASTM International, 2003.

21 ASTM B962-08, Standard test methods for density of compacted or sintered powder metallurgy (PM) products using Archimedes' principle, ASTM International, 2008.

22 K. Yang, H. R. Ma, X. Y. Liu and Q. He, Understanding wear interface evolution to overcome friction and restrain wear of TiAl-10 wt\%Ag composite, Adv. Eng. Mater., 2017, 1700637, 1-8.

23 S. S. Zhang, Y. J. Zhang and H. W. Wang, Effect of oxide thickness of solder powders on the coalescence of $\mathrm{SnAgCu}$ lead-free solder pastes, J. Alloys Compd., 2009, 487, 682-686.

24 J. P. Fan, B. Zheng, Y. Qin, D. Yang, D. D. Liao and X. K. Xu, A superparamagnetic $\mathrm{Fe}_{3} \mathrm{O}_{4}$-graphene oxide nanocomposite for enrichment of nuciferine in the extract of Nelumbinis Folium (Lotus leaf), Appl. Surf. Sci., 2016, 364, 332-339.

25 X. K. Huang, K. Y. Shi, J. Yang, G. Mao and J. H. Chen, $\mathrm{MnO}_{2}-$ GO double-shelled sulfur (S@ $\left.\mathrm{MnO}_{2} @ G O\right)$ as a cathode for Li-S batteries with improved rate capability and cyclic performance, J. Power Sources, 2017, 356, 72-79. 
26 K. Yang, H. R. Ma, X. Y. Liu, Y. M. Zhang and Q. He, Multiwalled carbon nanotubes enhanced the friction layer evolution and self-lubricating property of TiAl-10 wt\% Ag1 wt\% MWCNTs sample, RSC Adv., 2017, 7, 40592-40599.

27 K. Yang, X. L. Shi and W. Z. Zhai, Effects of $\mathrm{MoS}_{2}$ and multiwalled carbon nanotubes on tribological behavior of TiAl matrix composite, J. Mater. Eng. Perform., 2016, 25, 1094-1102.
28 K. Yang, X. L. Shi and A. Zhang, Effect of multiwalled carbon nanotubes on the lubricating properties of TiAl-Ag composites based on the changes in applied loads and testing temperatures, $R S C A d v .$, 2016, 6, 74269-74277.

29 W. Z. Zhai, W. L. Lu and P. Zhang, Microstructure, mechanical and tribological properties of nickelaluminium bronze alloys developed via gas-atomization and spark plasma sintering, Mater. Sci. Eng., A, 2017, 707, 325-336. 